and the patient removed direct from the bedroom into the country, the result being a rapid and complete recovery.

The features in this case to which I would draw attention are: (1) The advent of the rigors and fever immediately on being exposed to sewer gas, and their remarkable departure when removed to an airy upstairs room comparatively free from it. I tremble to think what would have been the result had the labour taken place in the contaminated downstairs room. (2) The fact that, although the rigors continued during a period of three weeks, no pus was formed, as was evidenced by the complete and rapid recovery of the patient when removed to healthy surroundings.

The chief lesson that the above three cases teach is that we must not look upon the occurrence of repeated rigors in a patient who is not the subject of a malarial fever as of necessity the result of an abscess, or even of a purulent inflammation. A rigor I believe to be simply the danger signal hoisted by nature when a poison enters the blood, or, I ought perhaps rather to say, when a poison has not only entered the blood, but has succeeded in so far making good its lodgment as to alter its character. Thus may we regard the initiatory rigor of the specific fevers, where one rigor is generally all that takes place, because the poison only makes one entrance. Thus, in malaria, probably each rigor represents each time that the malarial poison succeeds in modifying the general blood. This takes place, I believe, when rigors occur during the course of a purulent collection upon each entrance of pus into the general circulation, and the same, no doubt, occurred in the three cases narrated. In the first case, probably a rigor occurred at each fresh inoculation from the primary disease in the liver; in the second, at each syphilitic modification taking place in the blood itself, until checked by the iodide of potassium; and in the third, evidently upon each entrance of sewer gas into the already enfeebled pnerperal woman. Of course I do not mean that all rigors are due to blood-poisoning. Some are of nervous origin, and I well remember a case related by Sir James Paget in a clinical lecture, in which persisting rigors were due to an overlooked urethral stricture. The object of this paper, however, has been to try to prove that one must not too exclusively look upon rigors when they occur apart from the specific fevers and malaria as the indications of pus, but must be on the alert for any blood poison. Bradford.

\section{(illinical atotes:}

\section{MEDICAL, SURGICAL, OBSTETRICAL, AND THERAPEUTICAL.}

\section{IRPIGATION OF THE BLADDER IN CYSTOSCOPY.}

By Berkeley HILl, M.B., F.R.C.S. ENG.,

PROFESSOR OF CLINICAI SURGERY, UNIYERSITY COLLEGE, AND SURGEON TO THE HOSPITAI.

A CHIEF difficulty attending the inspection of the interior of the bladder in cystitis or with bleeding affections is that of keeping the watery contents transparent. Washing the bladder before the introduction of the cystoscope clears away much of the turbidity; but some purulent mucus remains attached to the inflamed and ulcerated surfaces or entangled in depressions, which floats off bit by bit and obscures the view. Moreover, the bleeding surfaces of a tumour or of an ulcer soon furnish enough blood to render the injected water as hazy as a London foo.

Messrs. Mayer and Meltzer have made, nnder my direction, a straight double catheter, with a sectional form of one-third of a circle (see accompanying drawing). This lies closely against the cystoscope, and can be introduced along with that instrument into the bladder. The tip of the catheter catches against a little nick at the heel of the bend of the cystoscope, and an elastic band round the bwo instruments near the handles keeps them in close contact during their passage along the urethra, which need not be at all painful. When the eyes of the catheter are fairly beyond the prostate, a current of solution of boracic acid (or of weak sulpho-carbolate of zinc should bleeding be troublesome) flows from an irrigator held three or four feet above the patient. In a few minutes the turbid urine is washed away, and the contents of the bladder keep perfectly clear as long as the current is maintained, without interfering at all with the movement of the cystoscope.

I find Nitze's own cystoscope, made by Hartwig of Berlin, more convenient for searching the bladder than Leiter's modification, known as the Leiter-Nitze cystoscope. Leiter's is a patented article, and therefore can be bought only of licensed agents. Nitze's instrument has a more suitable beak for turning in the bladder, shorter, and set on to the stem at a better angle. Briefly, it more closely resembles a well-shaped sound than the Leiter-Nitze. Also, the Nitze will revolve without dragging round with it the electric

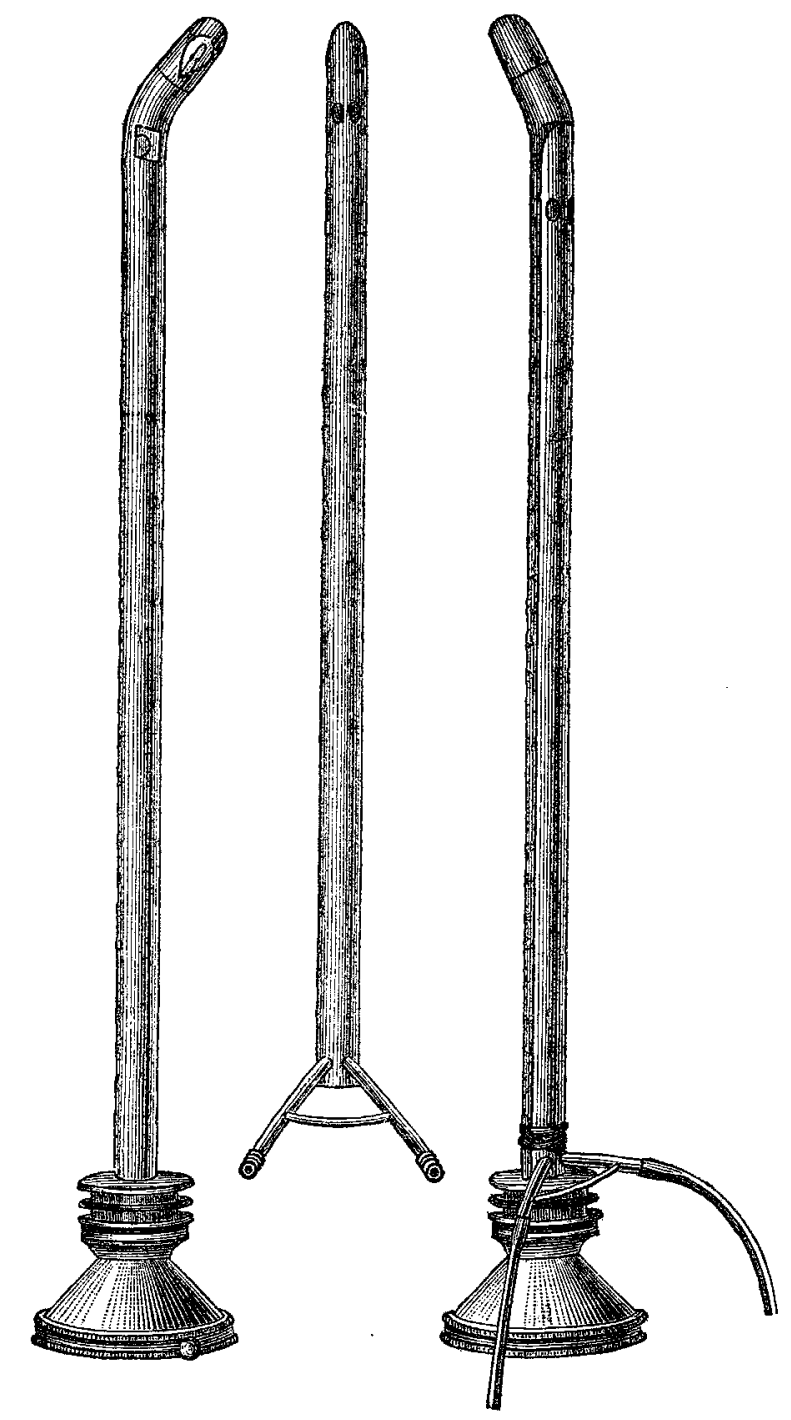

conductors-an advantage over Leiter's, where the instrument cannot be turned round in the bladder for the purpose of illuminating each portion without pulling the conductors after it. It is claimed for the Leiter-Nitze that a stronger lamp can be used with it than with the Nitze. My experience of the two instruments satisfies me that excellent illumination can be obtained with Nitze's, and its handier shape permits more free movement of it in the bladder. The stronger lampat the end of the long beak of the Leiter-Nitzesometimes touches the wall of the bladder and causes a painful sense of heat to the patient. Indeed, once my Leiter came in contact with a mass of coagulum, which it shrivelled into a cake that stuck fast to the lamp and shut in the light completely until the instrument was withdrawn and cleaned.

\section{SYMMETRICALLY GROUPED COMEDONES.}

\section{BY J. A. WETHERELI, M.B.}

IN THE LANCET of Oct. 13th last Dr. Thin gives a verbal description of three cases of grouped comedones, all of them in adults, together with a diagram illustrative of one of the cases. He considers that there is a by no means rare class of such. Dr. Radcliffe Crocker, in the issue of Oct. 27th, discusses the subject, and gives two figures. He seems to think that there are two distinct kinds or classes of comedones : one occurring in children, sometimes distributed irregularly - say on the face,-and occasionally in groupings; 
and a second and altogether different class affecting adults. Having just casually come across a case somewhat similar to that represented in Fig. 1. of Dr. Crocker's, I have determined to communicate it.

J. B-, aged thirty-seven years, is a hale, hearty man, who enjoys perfect health in every respect. He says he has suffered all his lifetime from the affection, and had made several unsuccessful attempts to cure himself. Immediately beneath each lower eyelid, and extending a little externally to the outer canthus, is a group of comedones, having the shape of an isosceles triangle, the base of which is directed outwards. They have an appearance as if grains of powder had been implanted on the skin, causing a disfigurement similar to what we sometimes see as the result of a gunpowder explosion. 'They are raised very slightly above the level of the surrounding skin, their summits being tipped with black, and about the size of a pin-point, all of them of a uniform height, and consequently on the same plane. In Dr. Thin's case we have a more extensive distribution, whilst in that of Dr. Crocker the apex of the triangle points outwards. I would suggest that grouped comedones as they affect adults and children are one and the same thing, depending only upon the time of life at which we happen to see them, for it is well known they may remain entirely unaltered for years. As to the etiology of these "symmetrically grouped comedones"-and observe that in my case the grouping is symmetry itself, exact and uniform-I, like Dr. Thin, have no explanation to offer, and must confess my inability even to suggest a probable causation. We find eczema and psoriasis almost always affecting, not one hand or side of the body alone, but both alike. Why this should be so we know not any more than we know why they should select any particular region of skin for their habitat. It may be that the regular grouping is attributable to a peculiarity of the blood supply of a part, that supply being subject to the ruling influence of certain nerve domains. But why should it be so? Perhaps, just as there are many kinds of eczema, one depending on the blood supply for its causation, another on the nerve supply, a third having a bacterial origin, whilst a fourth is purely local, - so there may be many varieties of comedones, each possessing a different fons et origo mali. I fear that until we discover more about the ultimate termination of nerve fibres in epithelial or other cells, and more about the circulation of ptomaines in, and expulsion from, the blood, we shall not advance much further in our knowledge of the pathology of either affection. When we have solved these problems we shall get a clearer view of the etiology of all skin diseases, and a better understanding as to the physiological indications of treatment. Inasmuch as the comedones in my case had existed from birth, evidently having had an intra-uterine existence, the proverbial and ineffaceable gout, with the whole train of digestive troubles bringing up the rear, could have had nothing to do with them. Barnsley.

\section{ON THE DILATATION OF THE PUPIL IN LOCO-} MOTOR ATAXY.

By ANGEL MONEY, M.D.

I HAVE several times observed a dilatation of the pupil in cases of locomotor ataxy in which the pupil did not contract to light. This dilatation only occurs, according to my observations, when the light employed in the search for the Argyll-Robertson symptom is intense, such a light as that used in the ophthalmoscope room. My impression has been that it is the intense light and heat acting upon the conjunctiva-i.e., fifth nerve-which is the cause of the dilatation of the pupil, just as is supposed to happen in stimulation of the skin of the neck by pinching or by the faradaic brush. But the dilatation due to intense light and heat is very small compared with that which usually obtains in health on irritating the skin. In the case of locomotor ataxy in which this dilatation of the pupil has been witnessed, pinching the skin of the neck on the side on which dilatation occurred from exposure to strong light and heat only caused a slight dilatation of the pupil. The pupils contracted when the eyeballs were convergent. It would be interesting to know whether the great heat of the lamp had as much to do with the production of the phenomenon as the intense light. In the cases in which I have observed this dilatation the pupils have not been very small.

Harley-street, W.
COCAINE IN CANCER OF THE BREAST.

By J. F. Somerville, L.F.P.S.G., L.A.H.D., L.M.

MRs. $\mathrm{B}$ - was operated on about two years ago by a prominent surgeon in London for cancer, the entire left breast. being removed. However, twelve months after the operation the disease reappeared, and developed so considerably that the same surgeon was again consulted and pronounced the case hopeless. Three months ago the usual intense pain which accompanies such cases set in, and it became simply a question of alleviating suffering. The usual remedies. having after a fair trial proved ineffectual, I tried a cocaine ointrnent ( 1 in 20). It had a marvellous effect; the pain. was subdued almost immediately and continually lept. under by its use. It had been used for two months, there. having been no occasion during that time even to increase. the strength. The patient expired on Monday, Dec. 24th, without the least suffering. I mention this, not knowing. whether it has before been used in such cases.

Swanage.

\section{d a dellirror}

of

\section{HOSPITAL PRACTICE, BRITISH AND FOREIGN.}

Nulla autem est alia pro certo noscendi via, nisi quamplurimas et mor. borum et dissectionum historias, tum aliorum tum proprias collectas habere, et inter se comparare.-MorgaGNI De Sed. et Caus. Morb., lib. iv. Procemium.

\section{HOSPITAL FOR SICK CHILDREN, GREAT ORMOND-STREET.}

A FIFTH CASE OF INTUSSUSCEPTION SUCCESSFULLY TREATED BY INFLATION.

(Under the care of Dr. CHEAdLE.)

THE treatment of cases of intussusception is a subject on which we have often dwelt in the columns of THE LANCET, and, as from time to time we receive further communica. tions demonstrating the effect of treatment, we give them. prominence, the subject being one of great importance. Brinton collected a series of 500 cases fatal from some form. of intestinal obstruction, and of these no less than 215 were due to invagination of the intestine. This is a very large proportion. Cases have been cured by means of the passing of gum-elastic bougies up the rectum, ${ }^{1}$ and copious injections. of warm water have proved successful. Maydieu of Argent ${ }^{2}$ used a mixture of No. 5 shot and olive oil, seven ounces of the former to four ounces of the latter, and quoted twelve. cases of supposed examples of the disease thus treated. He. has not found many imitators. Taliaferro records the case of a prisoner who was cured by the use of effervescing. powders placed in the rectum, but died of parotid bubo. some weeks later; his gaoler acted as medical adviser. Iced injections have also been tried. The method which is now usually employed, when these cases come under the observation of the physician, is that of infla. tion, first recommended by Gorham in $1838 .^{3}$ This, when combined with external manipulation, and the use of chloroform in children, often succeeds; it is not invariably successful, even if employed at an early stage of the disease: this must be remembered, and the patient vigilantly watched. Dr. Cheadle, in his remarks on a former case, says, "The success of inflation in the cure of intussusception depends largely, no doubt, upon its early employment. Higginson's syringe proved of most use." Fagge says on this subject: "It has now been frequently employed, and sometimes with the result of curing the disease. More. often, perhaps, its success has been partial. The tumour has been reduced in size, or it has changed its position, returning towards the seat which it had occupied at an earlier period." Too great care cannot be taken in its employment; trials should not be too prolonged norviolent in-

\footnotetext{
1 Fagge, vol. ii., p. $413 . \quad 2$ THE LANCET, vol. i. 1870, p. 737.
}

4 The LANCET, Mirror of Hospital Practice, vol. i. 1888, p. 321. 5 Op. cit 